\title{
Clinical outcomes of Transepithelial photorefractive keratectomy to treat low to moderate myopic astigmatism
}

\author{
Lei $\mathrm{Xi}^{1}$, Chen Zhang ${ }^{2}$ and Yanling $\mathrm{He}^{3^{*}}$ (D)
}

\begin{abstract}
Background: To evaluate the refractive and visual outcomes of Transepithelial photorefractive keratectomy (TransPRK) in the treatment of low to moderate myopic astigmatism.

Methods: This retrospective study enrolled a total of 47 eyes that had undergone Transepithelial photorefractive keratectomy. Preoperative cylinder diopters ranged from $-0.75 \mathrm{D}$ to $-2.25 \mathrm{D}$ (mean $-1.11 \pm 0.40 \mathrm{D}$ ), and the sphere was between $-1.50 \mathrm{D}$ to $-5.75 \mathrm{D}$. Visual outcomes and vector analysis of astigmatism that included error ratio (ER), correction ratio (CR), error of magnitude (EM) and error of angle (EA) were evaluated.

Results: At 6 months after TransPRK, all eyes had an uncorrected distance visual acuity of 20/20 or better, no eyes lost $\geq 2$ lines of corrected distant visual acuity (CDVA), and $93.6 \%$ had residual refractive cylinder within $\pm 0.50 \mathrm{D}$ of intended correction. On vector analysis, the mean correction ratio for refractive cylinder was $1.03 \pm 0.30$. The mean error magnitude was $-0.04 \pm 0.36$. The mean error of angle was $0.44^{\circ} \pm 7.42^{\circ}$ and $80.9 \%$ of eyes had axis shift within $\pm 10^{\circ}$. The absolute astigmatic error of magnitude was statistically significantly correlated with the intended cylinder correction $(r=0.48, P<0.01)$.
\end{abstract}

Conclusions: TransPRK showed safe, effective and predictable results in the correction of low to moderate astigmatism and myopia.

Keywords: Transepithelial photorefractive keratectomy, Myopia, Astigmatism

\section{Background}

Refractive errors, such as myopia and astigmatism, are the main cause of visual impairment throughout the world. A European adult population-based study found that myopia was in $35.1 \%$ of the participants and astigmatism $>0.5$ cylinder diopter (D) was in 32.3\% [1]. A prevalence and characteristic of corneal astigmatism (CA) in congenital cataract patients study reported that $39.25 \%$ of subjects had CA values $>2$ D [2]. Another study found that $22 \%$ had $C A \geq 1.5 \mathrm{D}$ or higher [3].

Surgical correction of spherical and cylindrical refractive errors has led to a decrease in complications as the improvement of recent technology. Accurate correction especially astigmatism is crucial to achieve better refractive

\footnotetext{
* Correspondence: heyanling2002@sohu.com

${ }^{3}$ Department of Ophthalmology, Peking University People's Hospital, Beijing, China

Full list of author information is available at the end of the article
}

outcomes. However, treatment of astigmatism is still a challenge. Transepithelial photorefractive keratectomy (TransPRK) is popularly chosen for its flapless feature and all-in-one step procedure. Several studies have evaluated the refractive and visual outcomes after TransPRK [4-7]. As for the correction of astigmatism, refractive surgeons are concerned more on the difference between small-incision lenticule extraction (SMILE), femtosecond lenticule extraction (FLEx) and wavefrontguided LASIK [8-11]. However, very few studies have focused on the efficacy of correcting astigmatism by TransPRK, especially in the vector method $[12,13]$.

The aim of this study was to evaluate the results of TransPRK in the correction of low to moderate myopic astigmatism by vector method.

(C) The Author(s). 2018 Open Access This article is distributed under the terms of the Creative Commons Attribution 4.0 International License (http://creativecommons.org/licenses/by/4.0/), which permits unrestricted use, distribution, and reproduction in any medium, provided you give appropriate credit to the original author(s) and the source, provide a link to the Creative Commons license, and indicate if changes were made. The Creative Commons Public Domain Dedication waiver (http://creativecommons.org/publicdomain/zero/1.0/) applies to the data made available in this article, unless otherwise stated. 


\section{Methods}

\section{Patient population and study design}

The retrospective study comprises 47 eyes of 36 patients with myopia ( -1.50 to $-5.75 \mathrm{D})$ and astigmatism $(-0.75$ to $-2.25 \mathrm{D}$ ) [14] who received TransPRK between October 2016 and January 2017 at the department of ophthalmology of Peking University. The demographic data for the patients were in Table 1. All patients were provided written informed consent. The study protocol was in accordance with the Declaration of Helsinki and institutional review board.

All enrolled patients underwent a complete ophthalmic examination and had no ocular diseases except myopic astigmatism. Preoperative examinations included slitlamp biomicroscopy, uncorrected distance visual acuity (UDVA), corrected distance visual acuity (CDVA), corneal topography (Optikon SpA, Rome, Italy), pentacam scheimpflug topography (Oculus, Wetzlar, Germany), manifest refraction, ultrasound pachymetry and dilated funduscopy examination. Patients with CDVA under $20 / 20$, suspicion of keratoconus and thin cornea thickness were excluded.

\section{Surgery}

The surgery was performed by a single surgeon using the SCHWIND Amaris 500E excimer laser platform (SCHWIND eye-tech-solutions GmbH, Kleinostheim, Germany). Ablations were based on aberration-free algorithms calculated using ORK-CAM software. The ablation profile targets epithelial thickness as $55 \mu \mathrm{m}$ centrally and $65 \mu \mathrm{m}$ peripherally according to the population model statistics [6]. Before ablation, all patients' examinations were tested by the statistic cyclotorsion control (SCC) and dynamic cyclotorsion control (DCC) was used through the surgery. After ablation, the corneal stromal was irrigated with a cool balanced salt solution and a soft bandage contact lens was applied.

After surgery, the patients were treated with topical 0.5\% levofloxacin (Cravit; Santen, Inc) eye drops four times a day for one week, $0.1 \%$ fluorometholone (Allergan, Inc) eye drops four to six times daily (tapered over 12 weeks) and preservative-free artificial tears four times daily for at least 6 months. The contact lens were removed once the epithelial closure was completed.

Table 1 Demographic Data for the Cohort of Eyes

\begin{tabular}{lll}
\hline Parameter & Mean \pm SD & Age Range \\
\hline Age $(y)$ & $30.69 \pm 4.85$ & $19-38$ \\
Gender & & \\
$\quad$ Male (n) & $33.60 \pm 3.57(10)$ & $26-37$ \\
Female (n) & $29.58 \pm 4.86(26)$ & $19-38$ \\
\hline
\end{tabular}

SD standard deviation, SE spherical equivalent refraction

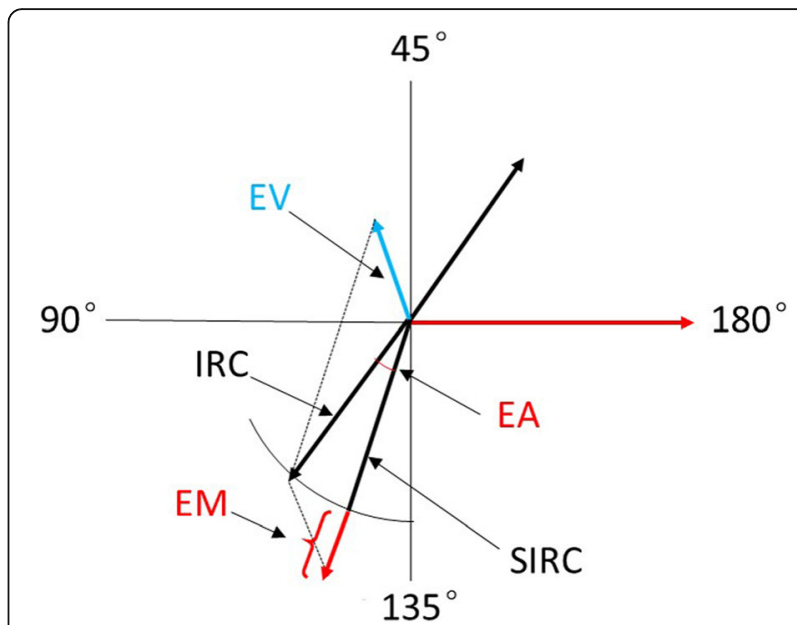

Fig. 1 Basic astigmatic vector quantities and relationships. EA: Error of angle; EV: Error vector; EM: Error of magnitude; IRC: Intended refractive correction; SIRC: Surgically induced refractive correction

\section{Main outcome measures and vector method}

The main outcomes include UDVA, CDVA, manifest refractive cylinder and sphere preoperatively and 6 months postoperatively.

Vector analysis of corneal astigmatism is based on the definitions and formulas given by Eydelman MB [15]. The vector quantities and data used in the astigmatic analysis are shown in Fig. 1 and defined as below:

The intended refractive correction (IRC) vector: the vector difference between the preoperative astigmatic correction vector and the target postoperative cylinder vector. If the target refractive state is emmetropia, the IRC vector is equal to the preoperative astigmatic correction.

Table 2 Summary statistics of refractive and visual outcomes

\begin{tabular}{llll}
\hline & $\begin{array}{l}\text { Preop } \\
\text { Mean } \pm \text { SD } \\
\text { (range) [median] }\end{array}$ & $\begin{array}{l}\text { G months } \\
\text { Mean } \pm \text { SD } \\
\text { (range) [median] }\end{array}$ & P-value \\
\hline Sphere(D) & $-3.87 \pm 1.15$ & $0.35 \pm 0.46$ & $<0.01$ \\
& $(-5.75$ to -1.50$)$ & $(-0.50$ to 1.25$)[0.25]$ & \\
& {$[-4.00]$} & & \\
Cylinder(D) & $-1.11 \pm 0.40$ & $-0.33 \pm 0.25$ & $<0.01$ \\
& $(-2.25$ to -0.75$)$ & $(-1.25$ to 0.00) $[-0.25]$ & \\
& {$[-1.00]$} & & $<0.01$ \\
MSE(D) & $-4.30 \pm 1.27$ & $0.18 \pm 0.46$ & \\
& $(-6.38$ to -0.88$)$ & $(-0.63$ to 1.13$)[0.13]$ & \\
& {$[-4.63]$} & & \\
CDVA(LogMAR) & $-0.10 \pm 0.07$ & $-0.14 \pm 0.07$ & \\
& $(-0.20$ to 0.00) & $(-0.20$ to 0.00) [-0.10] & \\
& {$[-0.10]$} & & \\
& $0.93 \pm 0.28$ & $-0.10 \pm 0.07$ & $(-0.20$ to 0.00) [-0.10]
\end{tabular}

MSE manifest spherical equivalent; CDVA corrected distance visual acuity; UDVA uncorrected distance visual acuity 

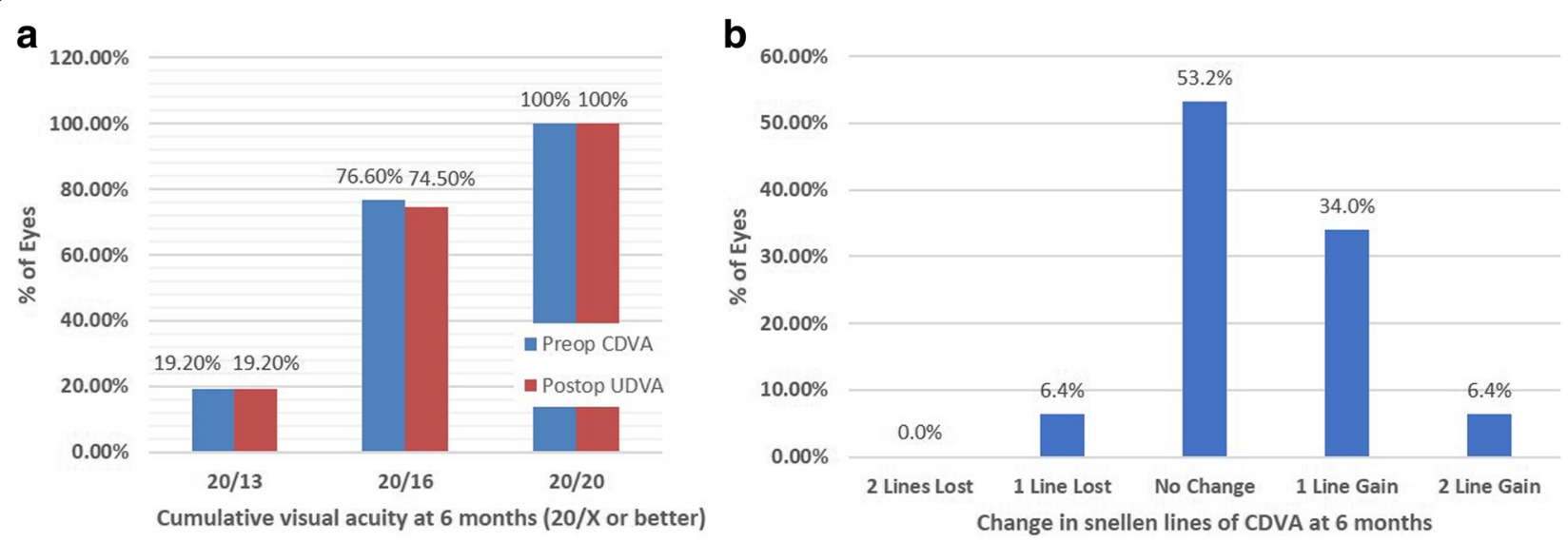

Fig. 2 Comparison of preoperative corrected distance visual acuity (CDVA) and postoperative uncorrected distance visual acuity (UDVA) (a). Change in snellen lines of CDVA at 6 months postoperatively (b)

The surgical induced refractive correction (SIRC) vector: the vector difference between the preoperative and postoperative astigmatic correction vectors. SIRC is the achieved correction.

The error vector $(\mathrm{EV})$ : the vector difference between the IRC and SIRC (IRC-SIRC), when the refractive target is emmetropia, the EV is equal to the postoperative astigmatic correction vector.

The error of magnitude (EM): the arithmetic difference of the magnitudes between SIRC and IRC ( | IRC | | SIRC | ).

The error of angle (EA): the angular difference between the achieved treatment and the intended treatment.

The correction ratio (CR): the ratio of the achieved correction magnitude to the required correction ( | SIRC $|/|$ IRC $\mid$ ). If the ratio $=1$, it is ideal. If $>1$, it means excessive application of the treatment. If $<1$, it means under correction.

\section{Statistical analysis}

Clinical data were analyzed using SPSS 20.0. Descriptive analysis with SDs for means was performed.
The distribution of the data was normality, the paired Student's $t$-test was used to analyze differences between preoperative and postoperative outcomes. Pearson correlation coefficient was used to analyze the correlation between the absolute EM and the intended cylinder correction. The relationship between the attempted refractive correction and achieved refractive correction was analyzed by linear regression analysis. A $p$-value $<0.05$ was considered statistically significant.

\section{Result}

This study included 47 eyes of 36 patients treated by TransPRK. The mean patient age was $30.69 \pm 4$. 85 years (range: 19 to 38 years). The preoperative and postoperative visual acuity (including UDAV and CDVA) and refractive outcomes such as sphere, cylinder, and spherical equivalent were summarized in Table 2. Significant improvement was observed between preoperative and 6 months postoperatively $(p<0.01)$.
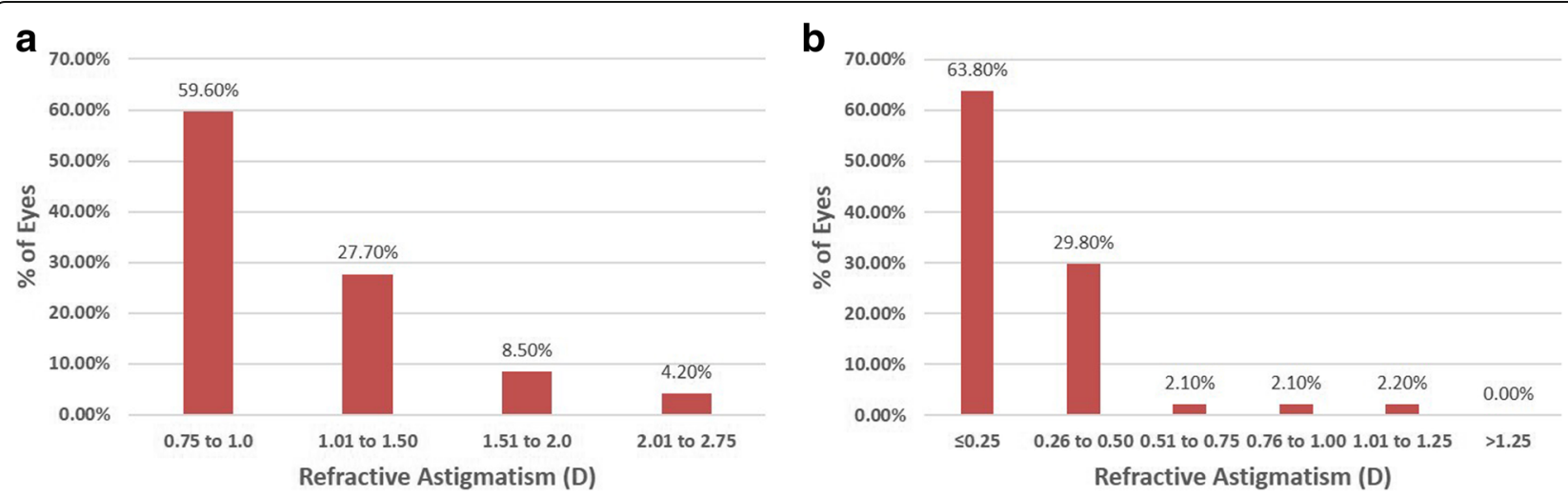

Fig. 3 Levels of astigmatism before (a) and after (b) transepithelial photorefractive keratectomy 
Table 3 Summary of residual refraction

\begin{tabular}{|c|c|}
\hline Residual magnitude & Percentage\%(eyes) \\
\hline$O D \leq \quad \mid$ Sphere $\mid \leq 0.5 \mathrm{D}$ & $72.3 \%(34)$ \\
\hline $0.5 \mathrm{D}<\quad \mid \quad$ Sphere $\mid \leq 1.0 \mathrm{D}$ & $21.3 \%(10)$ \\
\hline | Sphere|> 1.0D & $6.4 \%(3)$ \\
\hline $\mathrm{OD}<\mathrm{Cyl} \leq 0.5 \mathrm{D}$ & $93.6 \%(44)$ \\
\hline $0.5 \mathrm{D}<\mathrm{Cyl} \leq 1 \mathrm{D}$ & $4.3 \%(2)$ \\
\hline Cyl $>1 D$ & $2.1 \%(1)$ \\
\hline$O D \leq|S E| \leq 0.5 D$ & $68.1 \%(32)$ \\
\hline $0.5 \mathrm{D}<\quad|\quad \mathrm{SE}| \leq 1.0 \mathrm{D}$ & $27.7 \%(13)$ \\
\hline$|\mathrm{SE}|>1.0 \mathrm{D}$ & $4.2 \%(2)$ \\
\hline
\end{tabular}

$D$ diopter; Cyl cylinder; SE spherical equivalent

\section{Safety and efficacy}

At 6 months postoperatively, all of the eyes achieved the UCDV of $20 / 20$ or better visual acuity. No patient lost two or more lines of CDVA. Figure 2 shows the preoperative CDVA against postoperative UDVA and there was no significant difference between the two variables $(P=0.855)$. The changes in CDVA between preoperative and 6 months postoperative were shown in Fig. 2. 53.2\% (25 eyes) of eyes unchanged; $34 \%$ of eyes (16 eyes) gain one line, $6.4 \%$ of eyes ( 3 eyes) gain two lines and $6.4 \%$ (3 eyes) of eyes lose one line.

\section{Refractive outcomes}

The preoperative and postoperative astigmatic refraction was shown in Fig. 3. 63.8\% of the eyes with residual refractive cylinder $\leq 0.25 \mathrm{D}$. Summaries of the refractive status were in Table 3. The percentage of eyes with residual refractive cylinder $\leq 0.50 \mathrm{D}$ and $\leq 1.0 \mathrm{D}$ was in $93.6 \%$ (44 eyes) and $97.9 \%$ (46 eyes) respectively.

The linear regression of the scattergram was shown in Fig. 4. The achieved versus attempted spherical equivalent correction has a slop of 0.89 and the achieved versus attempted astigmatism correction has a slop of 1.09.

\section{Vector analysis}

Figure 5 shows the scattergram of cylinder preoperatively and the error of angle postoperatively. At 6 months, $51.1 \%$ of eyes with error of angle $\leq 5^{\circ}$ and $80.9 \%$ of eyes $\leq 10^{\circ}$. No eye more than $20^{\circ}$.

Summarizes of all vector parameters were in Table 4. The correction ratio for cylinder was $1.03 \pm 0.3$. The mean error of angle (EA) was $0.44 \pm 7.42^{\circ}$. The error of magnitude $(E M)$ was $-0.04 \pm 0.36 \mathrm{D}$.

\section{Discussion}

The evaluation of the myopic correction is significant in the clinic, especially in refractive surgery. TransPRK is recommended as one of the most advanced techniques for its flapless. Several previous studies have evaluated the safety, efficacy and predictability of TransPRK $[4,5,13,16]$. All of the eyes had postoperative UDVA 20/20 or better. $63.8 \%$ of the eyes with residual refractive cylinder $\leq 0.25 \mathrm{D}$, and $93.6 \%$ of the eyes $\leq 0.50 \mathrm{D}$. $80.9 \%$ of eyes with $\mathrm{EA} \leq 5^{\circ}$. One study found that $70.4 \%$ of eyes were within $\pm 0.25 \mathrm{D}$ and $87.0 \%$ of eyes were within $\pm 0.50 \mathrm{D}$ of the attempted cylindrical correction at 3 months followed SMILE surgery [11]. In addition, another study achieved $79.1 \%$ of eyes within $\pm 0.50 \mathrm{D}$ of intended correction of refractive cylinder [17]. The results of this study indicate that TransPRK in myopic eyes with low to moderate cylinder is safe, effective and predictable.
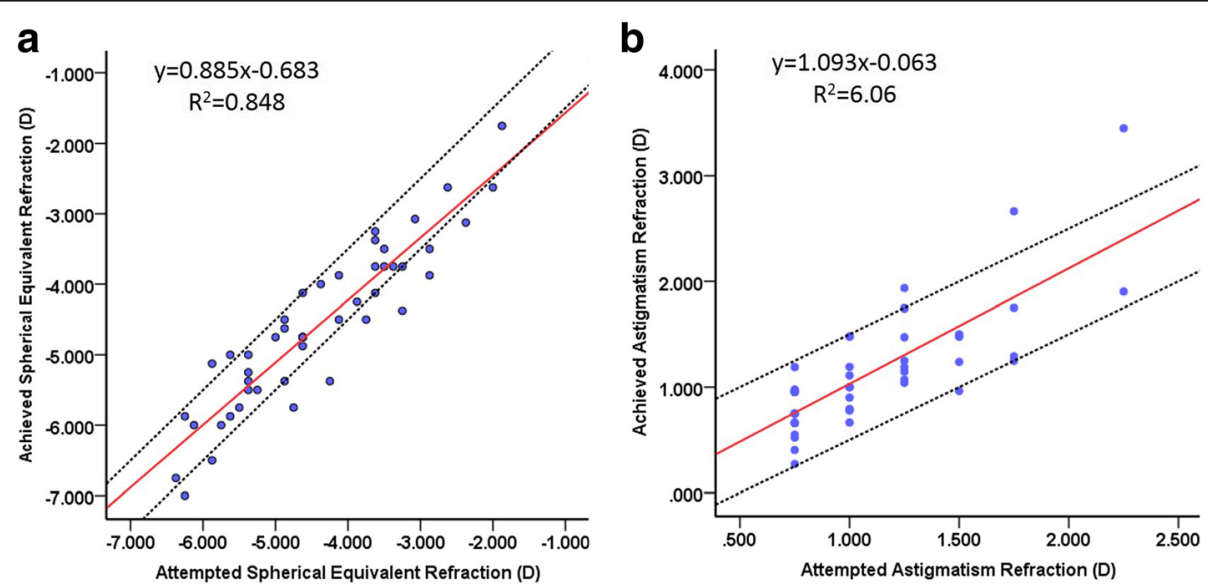

Fig. 4 Achieved versus attempted spherical equivalent corrections 6 months postoperatively (a). Achieved versus attempted astigmatism corrections 6 months postoperatively (b). The red solid line indicates the outcome of linear regression analysis, the area between two dotted lines mean within \pm 0.500 

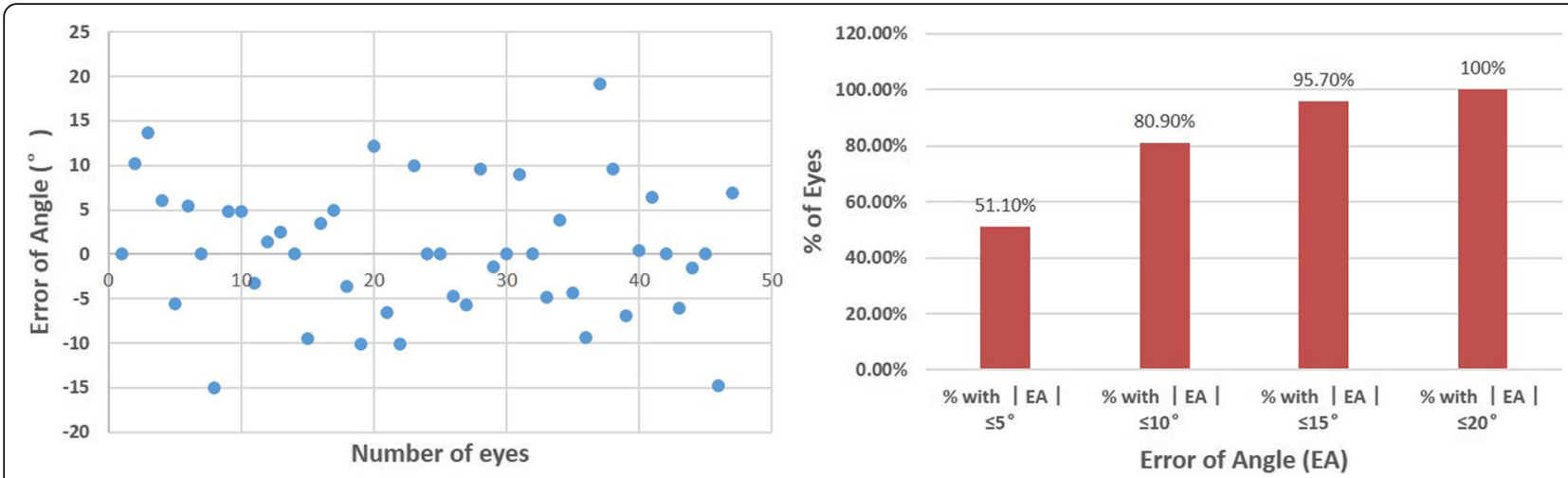

Fig. 5 Scatter diagram of Error Angle (EA) for 47 eyes (A). Summary of the EA between the achieved treatment and the intendent treatment

Other refractive surgeries had been analyzed in the correction of myopic astigmatism. It is difficult to compare because of the different degrees of refractive cylinder. Studies summarized in Table 5 [5, 8, 11, 12, 17-19] showed that we achieved favorable outcomes in comparison to the literature review. Adib et al. [5] reported that $97.26 \%$ of the eyes within $\pm 0.50 \mathrm{D} 18$ months later after the surgery of TransPRK for the correction of astigmatism. Similarly, Stojanovic et al. [12] achieved 79.1\% of eyes within $\pm 0.50 \mathrm{D} 12$ months later after TransPRK. Zhang $J$ et al. [17] found that $95.92 \%$ of eyes within $\pm 0.50 \mathrm{D}$ followed SMILE surgery.

Previous studies have attempted to evaluate the refractive outcomes by the spherical equivalent (SE). It is less precise because astigmatism includes both magnitude and axis direction. For this reason, vector analysis could describe the astigmatism correctly. Very few refractive surgery results such as small-incision lenticule extraction (SMILE), femtosecond lenticule extraction (FLEx) and LASIK had been analyzed in the vector method $[7,9,11,18,20]$. The aim of this study is to investigate the correction of low to moderate myopic astigmatism following TransPRK in vector method, which has not been reported until now.

Table 4 Vector analysis of changes in refractive cylinder

\begin{tabular}{lll}
\hline Vector parameter & $\begin{array}{l}\text { Eyes }(n=47) \\
\text { Mean (SD) }\end{array}$ & Range \\
\hline IRC (D) & $1.11(0.40)$ & $0.75-2.25$ \\
SIRC (D) & $1.15(0.57)$ & $0.27-3.45$ \\
ER & $0.30(0.19)$ & $0.00-0.667$ \\
CR & $1.03(0.3)$ & $0.36-1.59$ \\
EM (D) & $-0.04(0.36)$ & $-1.20-0.536$ \\
EA ( $\left.{ }^{\circ}\right)$ & $0.44(7.42)$ & $-15.00-19.13$ \\
\hline
\end{tabular}

$I R C$ intended refractive correction; SIRC surgically induced refractive correction; $E R$ error ratio; $C R$ correction ratio; $E M$ error of magnitude; $E A$ error of angle
The vector analysis of refractive cylinder showed slight overcorrection with the correction ratio (CR, ratio of the achieved correction magnitude to the required correction) of 1.03 at 6 months postoperatively. + 9\% overcorrection was observed in the linear regression of the attempted astigmatism refraction. The error of angle (EA) was anticlockwise and minimal $\left(0.44^{\circ}\right)$. Compare to other studies that use vector analysis of cylinder correction, Schallhorn et al. [7] found slight under correction of the refractive cylinder and a mean EA of $-0.45^{\circ} \mathrm{fol}-$ lowing wavefront-guided LASIK in the treatment of moderate-to-high astigmatism. Katz et al. [21] achieved a similar CA of 1.06 to our study, and the EA of $3.60^{\circ}$ in eyes with preoperative refractive cylinder greater than 3 . 00D. Chan et al. [11] found EA of $-0.85^{\circ}$ and $2.09^{\circ}$ in SMILE and femtosecond-assisted LASIK respectively in the correction of low to moderate myopic astigmatism. In this study, the error ratio of cylinder correction is 0 . 30, which is slightly higher than 0.13 reported by Schallhorn et al. [7]. These results indicate that TransPRK could achieve comparable results in the correction of cylinder by comparing with other surgeries. Statistic cyclotorsion control (SCC) and dynamic cyclotorsion control (DCC) may play an important role in the correction of cylinder.

The alignment is important for the refractive cylinder correction. Misalignment could result in both higher order aberrations (HOAs) and corrective performance $[18,22]$. In our study, $80.9 \%$ of eyes within the error of angle (EA) $\leq 10^{\circ}$, and $95.7 \%$ within $\leq 15^{\circ}$. One study found $68.4 \%$ of eyes had EA $\leq 10^{\circ}$ in a group of patients with preoperative refractive cylinder of $-0.90 \pm 0.68 \mathrm{D}$ followed SMILE surgery [18]. Another study found 98. $4 \%$ with EA within $10^{\circ}$ after wavefront-guided LASIK [7]. Although eye-tracking was used for every patient, the astigmatism axis could be misaligned by many factors. The cyclotorsional movements of the eyes from upright to supine position, the shift of the pupil center and the 
Table $\mathbf{5}$ Literature studies of myopic astigmatic correction

\begin{tabular}{|c|c|c|c|c|c|c|}
\hline Author (year) & Technique & Eyes $(n)$ & $\begin{array}{l}\text { Follow-up } \\
\text { (months) }\end{array}$ & Preoperative cylinder Mean \pm SD (range) & $\begin{array}{l}\text { Postoperative cylinder } \\
\text { Mean } \pm \text { SD (range) }\end{array}$ & Within 0.50D (\%) \\
\hline Schallhorn [17] (2015) & W-LASIK & 611 & 3 & $-2.76 \pm 0.81(-2.00$ to -6.00$)$ & $-0.37 \pm 0.38(-2.00$ to 0.00$)$ & $79.10 \%$ \\
\hline Stojanovic [12] (2013) & TransPRK & 117 & 12 & $-0.77 \pm 0.65(-4.50$ to 0.00$)$ & / & $94.00 \%$ \\
\hline Adib [5] (2016) & TransPRK & 146 & 18 & $-1.19 \pm 0.99$ & $-0.29 \pm 0.21$ & $97.26 \%$ \\
\hline Zhang J [18] (2015) & SMILE & 98 & 12 & $-0.90 \pm 0.68(-0.25$ to -2.75$)$ & $-0.20 \pm 0.27$ & $95.92 \%$ \\
\hline Al-Zeraid [19] (2016) & W-LASIK & 23 & 6 & $-3.22 \pm 0.59(-2.50$ to -4.50$)$ & $-0.72 \pm 0.46$ & $39 \%$ \\
\hline Ali-MA [8] (2014) & FLEX & 58 & 6 & $-0.97 \pm 0.54(-0.5$ to -2.75$)$ & $-0.26 \pm 0.37(-1.00$ to 0.00$)$ & $86 \%$ \\
\hline Chan [11] (2015) & SMILE & 54 & 3 & $-1.08 \pm 0.71$ & $-0.243 \pm 0.316$ & $87 \%$ \\
\hline Current study & TransPRK & 47 & 6 & $-1.11 \pm 0.40(-0.75$ to -2.25$)$ & $-0.33 \pm 0.25(-1.25$ to 0.00$)$ & $93.6 \%$ \\
\hline
\end{tabular}

W-LASIK wavefront-guided Laser in situ keratomileusis; TransPRK transepithelial photorefractive keratectomy; SMIL small-incision lenticule extraction; FLEx femtosecond lenticule extraction

large angle kappa occurred. In addition, the epithelial thickness ( $55 \mu \mathrm{m}$ centrally and $65 \mu \mathrm{m}$ periphery) estimated by the statistic of common people may lead to deep or shallow ablation of the corneal tissue. So, precise positioning center and epithelial mapping for every patient would be of great help for the precise correction of refractive cylinder.

In conclusion, the outcomes of this study suggest that TransPRK surgery is safe, effective and predictive in the treatment of low to moderate astigmatism. Based on the findings of our study, the absolute astigmatic error of magnitude was significantly correlated with the intended cylinder correction. Further investigation should be conducted to assess the treatment for correcting higher cylinder.

\section{Conclusions}

TransPRK surgery is safe, effective and predictable in the correction of low to moderate astigmatism.

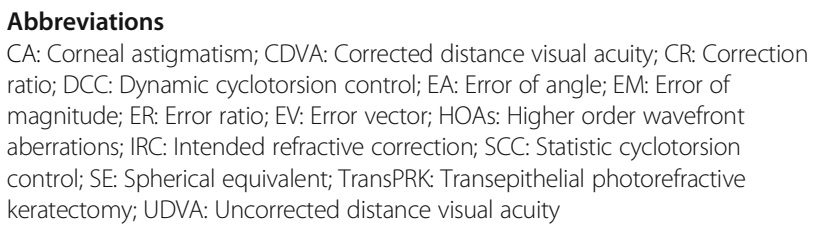

Abbreviations

CA: Corneal astigmatism; CDVA: Corrected distance visual acuity; CR: Correction ratio; DCC: Dynamic cyclotorsion control; EA: Error of angle; EM: Error of magnitude; ER: Error ratio; EV: Error vector; HOAs: Higher order wavefront aberrations; IRC: Intended refractive correction; SCC: Statistic cyclotorsion control; SE: Spherical equivalent; TransPRK: Transepithelial photorefractive keratectomy; UDVA: Uncorrected distance visual acuity

\section{Funding}

This study was not supported by any research grants.

\section{Availability of data and materials}

The data have not been placed in any online data storage. The datasets generated and analyzed during the study are available upon request from the first author.

\section{Authors' contributions}

Study concept and design (YLH, LX, CZ); collection, management, analysis, and interpretation of data ( $L X, C Z$ YLH); and preparation, review, or approval of the manuscript $(Y L H, C Z, L X)$. All authors read and approved the final manuscript.

\section{Ethics approval and consent to participate}

This study followed the tenets of the Declaration of Helsinki and approved by the ethics committee of the Department of Ophthalmology, Peking University International Hospital. Informed written consent was obtained from all participants

\section{Competing interests}

The authors declare that they have no competing interests.

\section{Publisher's Note}

Springer Nature remains neutral with regard to jurisdictional claims in published maps and institutional affiliations.

\section{Author details}

'Department of Ophthalmology, Peking University International Hospital, Beijing, China. ${ }^{2}$ Tianjin Medical University Eye hospital, Tianjin Medical University Eye Institute, School of Optometry and Ophthalmology, Tianjin, China. ${ }^{3}$ Department of Ophthalmology, Peking University People's Hospital, Beijing, China

Received: 10 January 2018 Accepted: 13 April 2018

Published online: 09 May 2018

\section{References}

1. Wolfram C, Höhn R, Kottler U, Wild P, Blettner M, Bühren J, et al. Prevalence of refractive errors in the European adult population: the Gutenberg health study (GHS). Br J Ophthalmol. 2014;98(7):857-61.

2. Lin D, Chen J, Liu Z, Wu X, Long E, Luo L, et al. Prevalence of Corneal Astigmatism and Anterior Segmental Biometry Characteristics BeforeSurgery in Chinese Congenital Cataract Patients. Sci Rep. 2016;6:22092.

3. Ferrer-Blasco T, Montes-Mico' R, Peixoto-de Matos S, Gonza'lez-Meı'jome JM, Cerviñ A. Prevalence of corneal astigmatism before cataract surgery. J Cataract Refract Surg. 2009:35:70-5.

4. Luger MH, Ewering T, Arba-Mosquera S. Myopia correction with transepithelial photorefractive keratectomy versus femtosecondLassisted laser in situ keratomileusis: one-year case-matched analysis. J Cataract Refract Surg. 2016:42(11):1579-87.

5. Adib-Moghaddam S, Soleyman-Jahi S, Salmanian B, Omidvari AH, AdiliAghdam F, Noorizadeh F, et al. Single-step transepithelial photorefractive keratectomy in myopia and astigmatism: 18-month follow-up. J Cataract Refract Surg. 2016;42(11):1570-8.

6. Arba Mosquera S, Awwad ST. Theoretical analyses of the refractive implications of transepithelial PRK ablations. Br J Ophthalmol. 2013;97:905-11.

7. Fadlallah A, Fahed D, Khalil K, Dunia I, Menassa J, El Rami H, et al. Transepithelial photorefractive keratectomy: clinical results. J Cataract Refract Surg. 2011;37(10):1852-7

8. Ali MA, Kobashi H, Kamiya K, Igarashi A, Miyake T, Elewa ME, et al. Comparison of astigmatic correction after femtosecond Lenticule extraction and Wavefrontguided LASIK for myopic astigmatism. J Refract Surg. 2014;30(12):806-11. 
9. Kobashi H, Kamiya K, Ali MA, Igarashi A, Elewa ME, Shimizu K. Comparison of astigmatic correction after femtosecond Lenticule extraction and small-incision Lenticule extraction for myopic astigmatism. PLoS One. 2015;10(4):e0123408.

10. Zhang J, Wang Y, Chen X. Comparison of moderate- to high-astigmatism corrections using WaveFront-guided laser in situ Keratomileusis and small-incision Lenticule extraction. Cornea. 2016;35(4):523-30.

11. Chan TC, Ng AL, Cheng GP, Wang Z, Ye C, Woo VC, et al. Vector analysis of astigmatic correction after small-incision lenticule extraction and femtosecondassisted LASIK for low to moderate myopic astigmatism. Br J Ophthalmol. 2016;100(4):553-9.

12. Stojanovic A, Chen S, Chen X, Stojanovic F, Zhang J, Zhang T, et al. One-step Transepithelial topography-guided ablation in the treatment of myopic astigmatism. PLoS One. 2013;8(6):e66618.

13. Antonios R, Abdul Fattah M, Arba Mosquera S, Abiad BH, Sleiman K, Awwad ST. Single-step transepithelial versus alcohol-assisted photorefractive keratectomy in the treatment of high myopia: a comparative evaluation over 12 months. Br J Ophthalmol. 2016;101:1106-12.

14. Richdale K, Berntsen DA, Mack CJ, Merchea MM, Barr JT. Visual acuity with spherical and toric soft contact lenses in low- to moderate-astigmatic eyes. Optom Vis Sci. 2007:84(10):969-75.

15. Eydelman MB, Drum B, Holladay J, Hilmantel G, Kezirian G, Durrie D, et al. Standardized analyses of correction of astigmatism by laser systems that reshape the cornea. J Refract Surg. 2006;22(1):81-95.

16. Kaluzny BJ, Cieslinska I, Mosquera SA, Verma S. Single-step Transepithelial PRK vs alcohol-assisted PRK in myopia and compound myopic astigmatism correction. Medicine (Baltimore). 2016:95(6):e1993.

17. Schallhorn SC, Venter JA, Hannan SJ, Hettinger KA. Clinical outcomes of wavefront-guided laser in situ keratomileusis to treat moderate-to-high astigmatism. Clin Ophthalmol. 2015;9:1291-8.

18. Zhang J, Wang Y, Wu W, Xu L, Li X, Dou R. Vector analysis of low to moderate astigmatism with small incision lenticule extraction (SMILE): results of a 1-year follow-up. BMC Ophthalmol. 2015;15:8.

19. Al-Zeraid FM, Osuagwu UL. Induced higher-order aberrations after laser in situ Keratomileusis (LASIK) performed with Wavefront-guided IntraLase femtosecond laser in moderate to high astigmatism. BMC Ophthalmol. 2016;16:29.

20. Biscevic A, Bohac M, Koncarevic M, Anticic M, Dekaris I, Patel S. Vector analysis of astigmatism before and after LASIK: a comparison of two different platforms for treatment of high astigmatism. Graefes Arch Clin Exp Ophthalmol. 2015;253(12):2325-33.

21. Katz T, Wagenfeld L, Galambos P, Darrelmann BG, Richard G, et al. LASIK versus photorefractive keratectomy for high myopic ( $>3$ diopter) astigmatism. J Refract Surg. 2013;29(12):824-31.

22. Wang L, Koch DD. Residual higher-order aberrations caused by clinically measured cyclotorsional misalignment or decentration during wavefrontguided excimer laser corneal ablation. J Cataract Refract Surg. 2008;34(12): 2057-62.

\section{Ready to submit your research? Choose BMC and benefit from:}

- fast, convenient online submission

- thorough peer review by experienced researchers in your field

- rapid publication on acceptance

- support for research data, including large and complex data types

- gold Open Access which fosters wider collaboration and increased citations

- maximum visibility for your research: over $100 \mathrm{M}$ website views per year

At BMC, research is always in progress.

Learn more biomedcentral.com/submissions 